(I) The mean value for the faraday, 96,538 coulombs, given in column XIII has a precision of $0.005 \%$. The average deviation of the individual results from the mean is $0.010 \%$ and the maximum is only $0.012 \%$. These deviations are caused by the silver coulometer, not by the iodine coulometer.

(2) The value $96,53^{8}$ agrees astonishingly well with the value, 96,535 , obtained by Richards with his copper conlometer (see Table I).

(3) The results with the iodine coulometer confirm the conclusion, already reached, that the silver deposit obtained in the silver coulometer, even under the best conditions, is greater than that required by the reaction, $\mathrm{Ag}^{+}+(-)=\mathrm{Ag}$.

(4) The value 96,538 coulombs per equivalent corresponds to the value I. I 74 milligrams per coulomb for the true electrochemical equivalent of silver. This is $0.08 \%$ lower than the value obtained by Smith, Mather and Lowry and $0.05 \%$ lower than the recent result of Rosa, Vinal and McDaniel (see Table I).

(5) Although we have no reason to believe that our results are affected by any source of error amounting to $0.03 \%$, they are, perhaps, too few in number to justify the conclusion that the value, 96,538 coulombs, is correct within this limit. We believe, however, that the evidence presented in the foregoing pages justifies the statement that the value of the faraday is certainly greater than 96,500 coulombs and that the true electrochemical of silver is certainly less than I.x I 80 milligrams per coulomb. We hope to be in a position to make a more definit statement during the coming year.

TRBAXA, ILL., TURe $2 \%, 1912$

\title{
PASSIVITY OF IRON UNDER BOILER CONDITIONS.
}

BY HORACE G. ByeRs AND FloYd T. VORIS.

Received August 10,1912.

\section{Introduction.}

The use of substances which inhibit the rusting of iron in order to protect it from the action of corrosive agents was suggested by Cushman, ${ }^{1}$ who says that "small quantities of inhibitive substances in boilers should be highly efficacious in preventing pitting." Wyatt ${ }^{2}$ suggests the use of sodium bichromate in boilers to precipitate the scale-forming materials and states that the chromic acid formed does not attack the iron. On the other hand, Schoch and Randolph ${ }^{3}$ state that " the corrosive character of an aqueous solution cannot be extensively lessened by additions of certain electrolytes such as chromates, hydroxides, etc." Also it was shown by one of $u^{4}$ that in many solutions, in which iron as an anode is

${ }^{1}$ Office Public Roads, U. S. Dept. Agric., Bull. 30, 29.

Eng. Min. J., 60, 220.

"I. Physic. Chem, 14,719 .

- Byers. Jms JonRnal, 30, ipr8. 
passive at ordinary temperatures, the passive state is destroyed at temperatures ranging from $60^{\circ}$ to $80^{\circ}$, and that it is impossible to render iron passive in halogen salt solutions by the use of anodic current density alone. It therefore seemed to be of interest to determin which of these views, (Cushman vs. Schoch), neither of which is adequately supported, is verified experimentally. Since the work was begun two papers bearing on the problem have appeared. Dunstan and Hill, ${ }^{1}$ have shown that the presence of salt solutions destroys the passive condition of metals and that on the other hand iron could be obtained in a passive state in boiling potassium bichromate, sodium carbonate and potassium hydroxide. J. L. R. Hayden ${ }^{2}$ has shown that iron plates remain passive in the presence of $0.02 \%$ of ammonium chloride but corrode slightly in $0.04 \%$ of the same salt.

The present contr bution is an effort to go into the subject more thoroughly and at temperatures approaching those prevailing under steam boiler conditions. After the details of the experimental conditions and results are presented, a summary will be offered.

\section{Experimental.}

Figs. I and 2 show the apparatus devised to determin at what temperatures iron can be kept passive as an anode in bichromate solutions of various concentrations and the arrangement of the coulometer, ammeter,

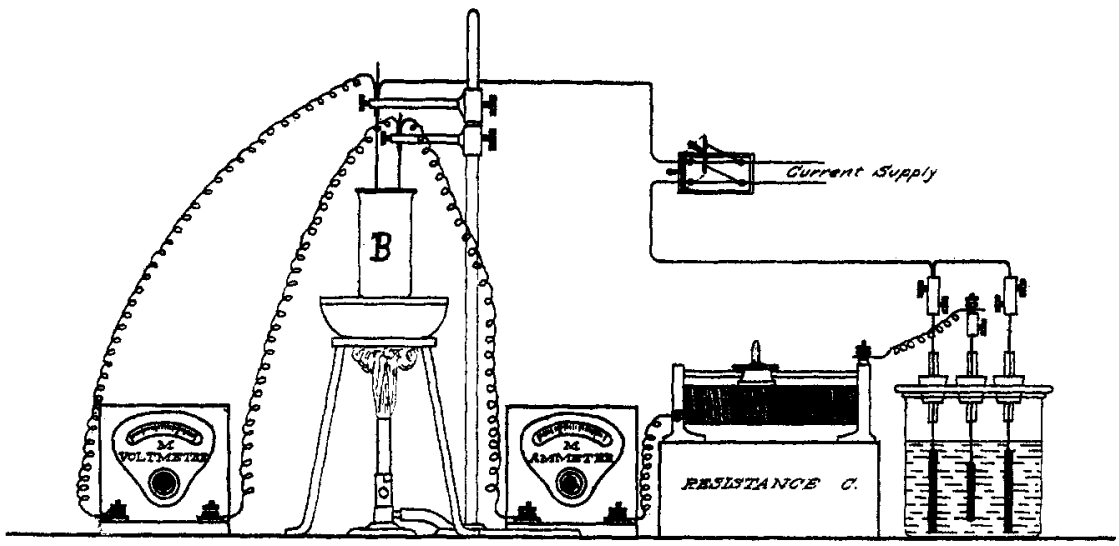

Fig. I.

voltmeter, etc., to measure the anode loss and current used. In Fig. 2 is shown a boiler which consists of a heavily capped piece of gas pipe, the upper cover of which is pierced with two holes, $1 / 2$ inch in diameter, to carry the anode and cathode. The boiler also carries a pressure gauge and safety valve and a broad base in order that it may set securely in a

${ }^{1} J$. Chem. Soc., 99, 1835.

${ }^{2}$ J. Frank. Inst., 172, 295. 
large paraffin bath. The cathode and anode consist of standard iron wire $(99.8 \%)$ of about $0.7 \mathrm{~mm}$. diameter, sealed in glass tubes and passed through corks securely plugged into the cover of the boiler. The area of the anodes was calculated from the diameter of the wire and the length

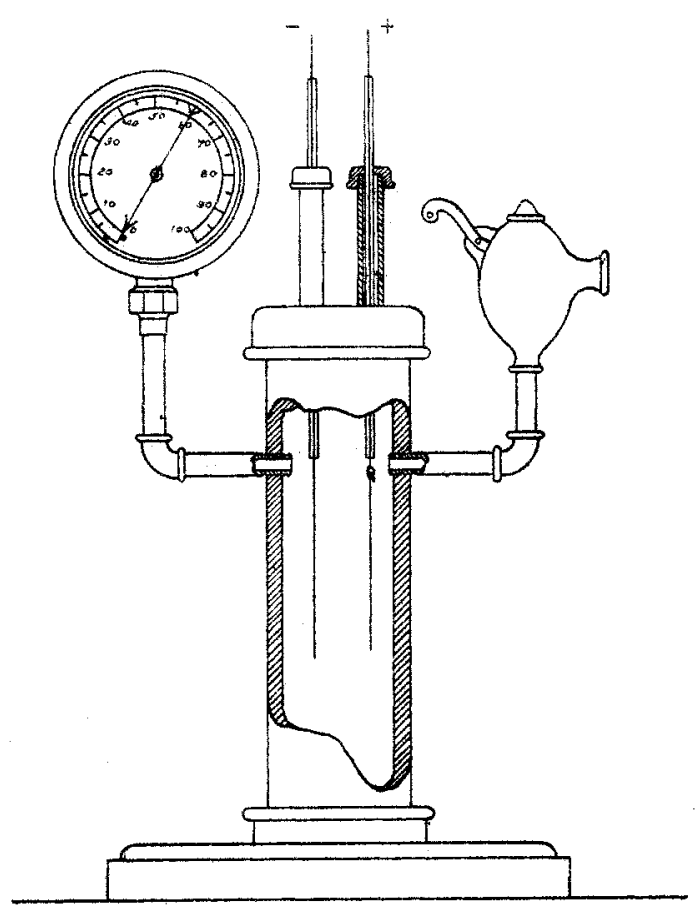

Fig. 2 . of the portion immersed, but because of the difficulty of exact determination of this latter quantity, the density per sq. cm. given in the tables is only approximate. The current used was determined approximately by means of a milliammeter graduated to read to tenths and the amount regulated by a slide wire resistance. To get exact values the current used was measured by means of a copper coulometer with a variable cathode. In conducting the experiments a voltmeter was connected with the electrodes and a key in order to determin when the anode was passive. The readings are not recorded since the voltages have no other significance than to indicate when the iron goes into the passive condition. When active the potential fall between the electrodes was below $2.5 \mathrm{v}$, and when passive upwards of $4 \mathrm{v}$, varying of course with the concentration of the electrolytes used and with the current strength employed. Where temperatures of less than $100^{\circ}$ are involved the boiler was replaced by a porcelain beaker ( $B$. Fig. I) and when this was used at or near boiling temperature the level of the electrolyte was maintained as accurately as possible by means of a hot water bottle. Temperatures were determined by a thermometer immersed in the bath close to the boiler and, as the rise of temperature in heating the bath was very gradual, represent very accurately the temperature of the electrolyte. The electrolytes used were prepared in the form of $5 \%$ stock solutions of the salts used and the various concentrations employed were obtained by placing the required volumes of each in a $200 \mathrm{cc}$. flask and diluting to the mark with distilled water. 
TABLE I.

\begin{tabular}{|c|c|c|c|c|c|c|c|c|}
\hline 0. & $\begin{array}{l}\text { Per cent of } \\
\mathrm{K}_{2} \mathrm{Cr}_{2} \mathrm{O}_{7}\end{array}$ & $\begin{array}{c}\text { Tempera- } \\
\text { ture. }\end{array}$ & $\begin{array}{l}\text { Time } \\
\text { in min. }\end{array}$ & $\begin{array}{l}\text { Weight of } \\
\text { copper } \\
\text { deposited. }\end{array}$ & $\begin{array}{l}\text { Weight of } \\
\text { iron lost. }\end{array}$ & $\begin{array}{c}\text { Current in } \\
\text { milliam- } \\
\text { peres. }\end{array}$ & $\begin{array}{l}\text { Milliam- } \\
\text { peres } \\
\text { per sq. cm. } \\
\text { anode. }\end{array}$ & \\
\hline 1 & 2.5 & 80 to II 3 & 39 & 0.03048 & 0.00048 & 39.57 & 52.9 & Passive \\
\hline 2 . & 4.0 & 100 to 135 & 75 & 0.00810 & 0.00005 & & & \\
\hline 3. & 2.0 & 146 & $9 I$ & 00735 & . & & 5.24 & \\
\hline 4 . & I. $O$ & 33 to 151 & I I 6 & .09390 & $\cdots$ & 40.98 & $3 I$ & ve \\
\hline 5 . & 0. & 106 to 147 & 82 & 0.072 & 0.00024 & 7 & 40.6 & Passive \\
\hline & o. & to 120 & 120 & & & & & sive \\
\hline 7. & O.I 25 & 22 to 160 & 107 & 0.04831 & 0.00018 & 22.86 & 3 I. 48 & Passive \\
\hline
\end{tabular}

Table I gives the results obtained for bichromate solutions of a concentration varying from $4 \%$ to $0.125 \%$. The temperatures used varied from $80^{\circ}$ to $160^{\circ}$ and in all cases the iron is wholly passive; the minute losses and gain of weight being due to rusting above the area immersed in the electrolyte. In each case the iron was presumably active when immersed, being cleaned thoroughly either by pickling in dilute sulfuric acid or by scrubbing with fine emery paper. Temperatures above $160^{\circ}$ were not reached because of softening of the cork and loss of steam. Having thus determined that the solutions keep the iron passive at temperatures at and above $100^{\circ}$, the next step was to determin what concentration of sodium chloride is sufficient to destroy the inhibiting influence of bichromate. The results obtained at room temperature are shown in Table II. At all ratios of concentration of less than $40 \%$ bichromate to $\mathrm{I}$ of salt the iron remained active, but the loss of weight of iron is not given because the pitting and rusting were so great as to render cleaning of the anode impracticable. In two cases, Nos. I I and I2, the iron used was previously made passive by immersion in bichromate

TABLE II.

\begin{tabular}{|c|c|c|c|c|c|c|c|c|c|}
\hline$o$. & $\begin{array}{l}\text { Per cent } \\
\text { of } \\
\mathrm{K}_{2} \mathrm{Cr}_{2} \mathrm{O}_{7}\end{array}$ & $\begin{array}{l}\text { Per cent } \\
\text { NaCl. }\end{array}$ & $\begin{array}{l}\text { Ratio of } \\
\mathrm{K}_{2} \mathrm{Cr}_{2} \mathrm{O}_{7} \\
\text { to } \mathrm{NaCl}^{2}\end{array}$ & $\begin{array}{l}\text { Tem- } \\
\text { pera- } \\
\text { ture. }\end{array}$ & $\begin{array}{l}\text { Time } \\
\text { in min. } \\
\text { tites. }\end{array}$ & $\begin{array}{l}\text { Weight of } \\
\text { copper } \\
\text { deposited. }\end{array}$ & $\begin{array}{l}\text { Current } \\
\text { in milli- } \\
\text { axpores. }\end{array}$ & $\begin{array}{l}\text { per sq. } \\
\mathrm{cm} \text {. of } \\
\text { iron } \\
\text { anode. }\end{array}$ & $\begin{array}{c}\text { of anode } \\
\text { at close } \\
\text { of experi } \\
\text { ment. }\end{array}$ \\
\hline$x$. & I.O & 0.5 & $2 / 1$ & $21^{\circ}$ & 40 & 0.02565 & 32.53 & 52.8 & Active \\
\hline $2 \ldots$ & 1.0 & 0.25 & $4 / 1$ & 18.5 & $3 I$ & 0.02053 & & 56.5 & ive \\
\hline 3 . & 2.0 & 0.25 & $8 / 1$ & 19.0 & 40 & 0.02584 & & & ve \\
\hline 4. & 4.0 & o. & $16 / 1$ & 19. & 40 & 0.02840 & & & \\
\hline 5 . & 4.0 & 0.10 & $40 / 1$ & 2 & 40 & 0.02618 & 8 & & ive \\
\hline 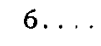 & 4.0 & 0. Io & $40 / 1$ & 9. & 32 & 0.02032 & I5 & 48.7 & ive \\
\hline 7 & 0.3125 & 0.025 & I2. $5 / \mathrm{I}$ & I 6 & 8 & 0.0 & & 24.8 & \\
\hline & 0.25 & 0.0225 & $20 / 1$ & 14.5 & II & 0.0 & 26 & $?$ & ve \\
\hline 0 & 0.375 & 0.0 & $30 / 1$ & I7 & II & & 71 & $?$ & ive \\
\hline 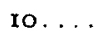 & 0.50 & 0.0125 & $40 / 1$ & I5 & 47 & & & 28.2 & ive \\
\hline & $0.3^{125}$ & 0.0125 & $25 / 1$ & I9 & 12 & Qual. & $(20.0)$ & & \\
\hline & 0.3125 & 0.0125 & $25 / 1$ & 16 & 40 & 0.01518 & $\mathrm{Ig} .2 \mathrm{I}$ & 26.4 & Active \\
\hline & 0.3125 & 0.0125 & $25 / 1$ & $2 I$ & 40 & 0.01495 & ig & 32.4 & Active \\
\hline & 0.3125 & 0.0078 & $40 / I$ & 20.5 & 45 & 0.02404 & 44 & 30.2 & Passive \\
\hline & 0.3125 & 0.0104 & $30 / 1$ & I9 & 30 & 0.01633 & 27.06 & 29.9 & Active \\
\hline
\end{tabular}


before beginning the experiment in the mixed electrolyte. These results are in accord with those obtained by Dunstan and $\mathrm{Hill}^{1}$ and by Hayden. ${ }^{\prime}$

The next step was to determin the ratio of $b$ chromate required to keep iron passive in salt solution at about boiling temperature. The temperature registered was $93^{\circ}$ as that was conveniently maintained without great loss of solution and without deposition of salts upon the wire outside the electrolyte. The fact previously shown (see introduction) that the general effect of elevation of temperature is to destroy passivity, naturally led us to expect that a larger ratio would be necessary. Quite the reverse was the case and the results given in Table III show that a ratio of 25 of bichromate to $\mathrm{I}$ of salt is sufficient to render the iron almost ii not quite wholly inactive. In Nos. I 2 and 13 a small degree of activity is observed but only a very small fraction of that demanded for accord with Faraday's law. In Nos. 4, 7 and 8 , it is seen that even a ratio of 20 to $\mathrm{I}$ is practically effective. In No. I 2 the solution used in No. I I was poured into a flask, which was filled, allowed to cool and used with the same electrodes. The anode was almost theoretically active, probably wholly so if the adhering oxide could be quantitatively removed. In No. I3 a cold solution of the ratio 25 : I showed itself wholly active in spite of the anode being previously rendered passive in pure bichromate solution, and when used hot as in No. I 4 was effective in producing the passive state.

The next step, the determination of the ratio at temperatures above roo ${ }^{\circ}$, was carried out with results as indicated in Table IV. Here again a somewhat surprising result is obtained. While a ratio of $40: 1$ (see Nos. $5,7,8$ ) is absolutely effective in inhibiting the activity of the iron even where the concentration is so small as $0.1 \%$ to $0.025 \%$, there is appreciable rusting at 35 to $I$ and yet the anode loss is not at all equal to that which takes place when iron is wholly active. The exact amount of loss is not indicated by the loss of weight recorded, since much oxide adheres even to the carefully cleaned anode, as in Nos. $I$ and 2 . The variation in temperature noted in the table is as follows: The boiler was immersed in hot parafin and when the temperature ceased to fall the current was allowed to pass through the electrodes. The higher temperatures were then gradually attained by continued heating and the apparatus kept at the highest mark for from fifteen minutes to half an hour, when leaks usually developed.

Since in the natural waters likely to be used for boiler purposes the only substances other than chlorides which would remain in solution after treatment with bichromates, are sulfates and carbonates of the alkalies, 


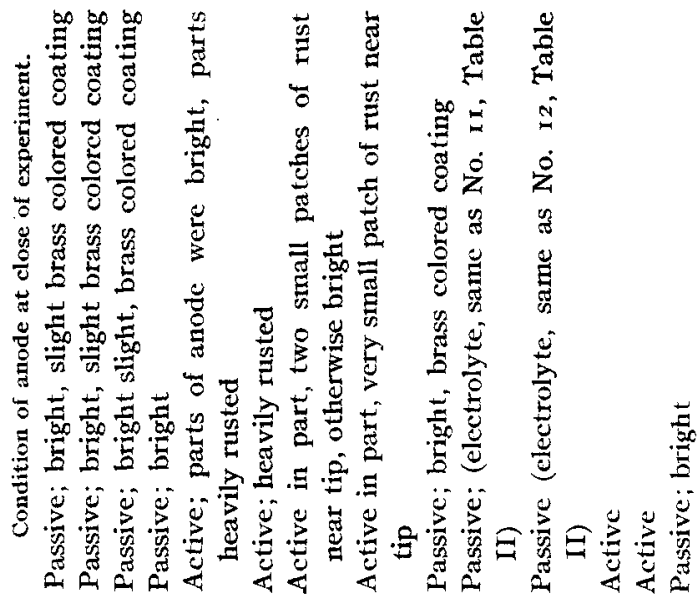

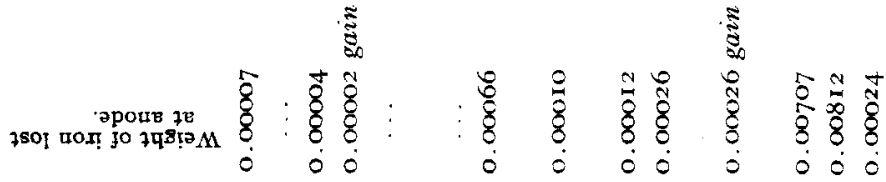

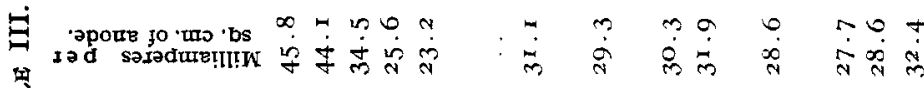

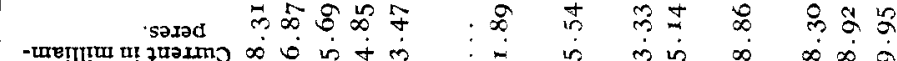

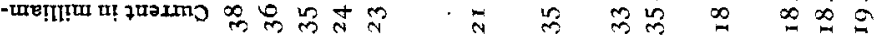

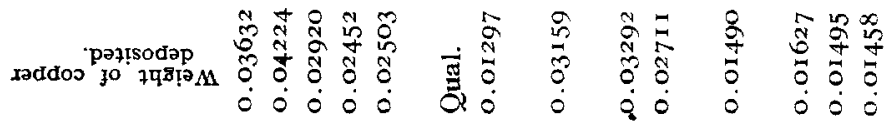

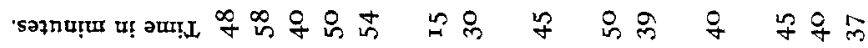

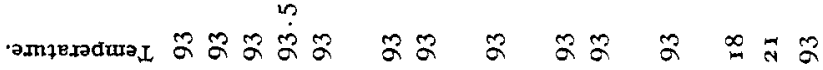

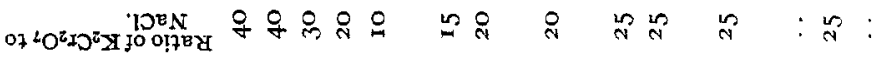

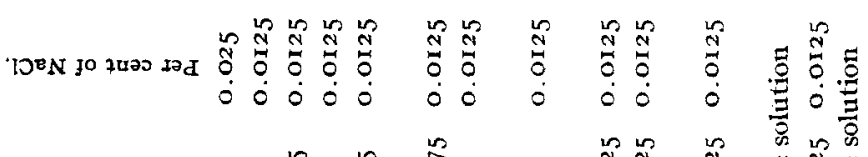

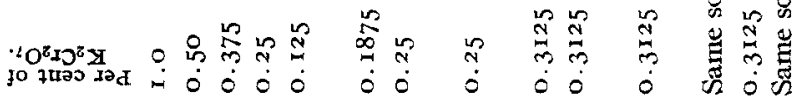

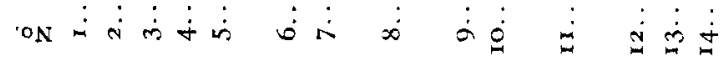




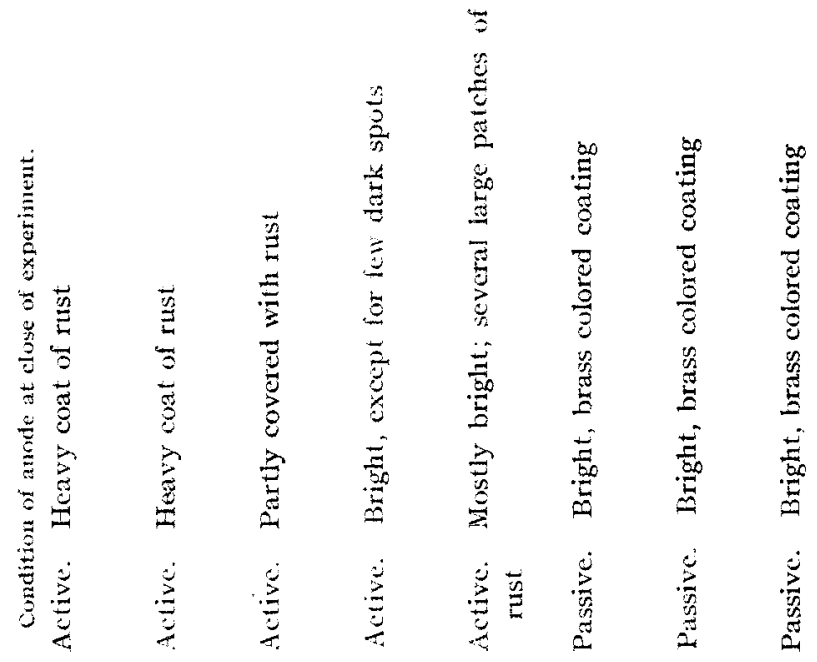

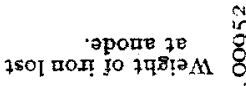

$\begin{array}{lll}\infty & 0 \\ 0 & 0 \\ 0 & 0 & 0\end{array}$

$\hat{\mathrm{Q}} \quad \hat{\mathrm{Z}}$

$\begin{array}{lll}2 & 0 \\ 0 & 0 & 8\end{array}$

$>$ oporre jo taro bs in

in

xod seredareititi $\Rightarrow$ क

$\stackrel{\infty}{\infty}$

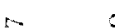

$\because$

in

$\underline{4}$

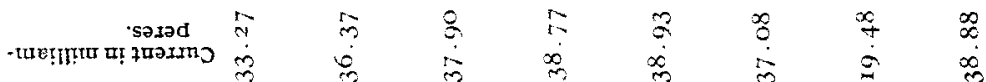

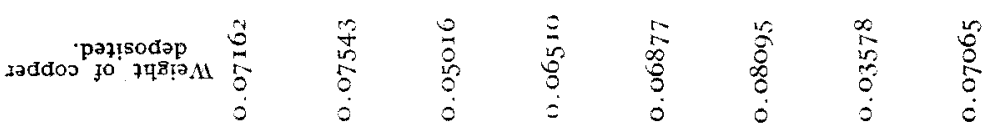

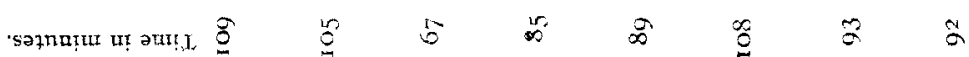

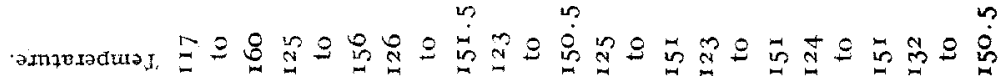

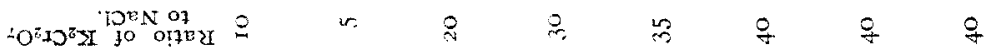

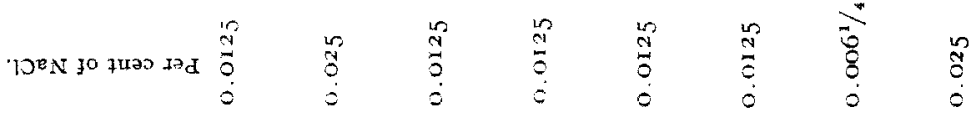

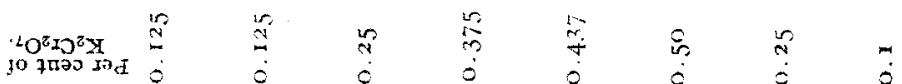


a series of tests was made to determin the ratio of bichromate to sulfate which would keep iron passive.

Some additional interest attaches to these experiments since Dunstan and Hill, ${ }^{1}$ whose paper appeared during the progress of the work, state that sulfates and nitrates as well as chlorides render iron active when added to solutions in which it is passive. That nitrates do not necesdarily do so is shown sufficiently by the experiments of Hayden ${ }^{1}$ when he shows that $\mathrm{i} \%$ of potassium nitrate will be sufficient to keep iron passive in $0.02 \%$ of ammonium chloride. He also shows that $0.5 \%$ of bichromate will keep iron passive in the presence of $1 \%$ of ammonium sulphate. Table $V$ shows that with a ratio of $I$ to $I$, bichromate and sodium sulfate, the iron is always practically passive, not only at ordinary temperatures but at near the boiling point and at about $150^{\circ}$. When the concentration ratio is less than $I: I$ the influence of current density in producing the passive state becomes evident as may be seen by reference to Nos. 6 and 7 , and also to Nos. I 8 and 19 , where the only difference discernable is that of the density of the current employed.

Table VI contains the results obtained, at the temperatures indicated, with bichromate and various concentrations of sodium carbonate. It would not have been necessary to have performed these experiments in view of the results previously obtained by one of $u^{2}$ but for the work of Krassa, ${ }^{3}$ in which it was shown that iron is apparently active as an anode at elevated temperatures in hot, strong solutions of sodium hydroxide if the current density is not too great. It will be seen from the results that at all the temperatures and concentrations and variations of current density used the iron could not be made to rust, this passivity is produced despite the fact that the anodes were carefully made active by dipping in dilute sulfuric acid until hydrogen began to be liberated and then were washed and dried. Connections were also made by immersion of the cathode and closing the circuit by means of the anode. No. I2 of the table shows that iron is passive, even with the slight current employed, in a sodium hydrogen carbonate solution at $93^{\circ}$.

A few experiments were made to determin if iron is normally passive in water containing free carbonic acid. The results were negative. With current densities varying from 0.4 to 75 milliamperes per sq. cm. of anode the iron remained active throughout at room temperature. The statement of Dunstan and Hill ${ }^{1}$ that iron does not rust in the absence of air even when immersed in sodium chloride solution, led to some successful experiments to determin if the anodic passivity could be established in a salt solution in the absence of air. It has already been shown by Byers ${ }^{1}$

\footnotetext{
1 Loc. cit.

2 Byers, Loc. cit.

${ }^{3} Z$. Elektrochem., 15, 490.
} 

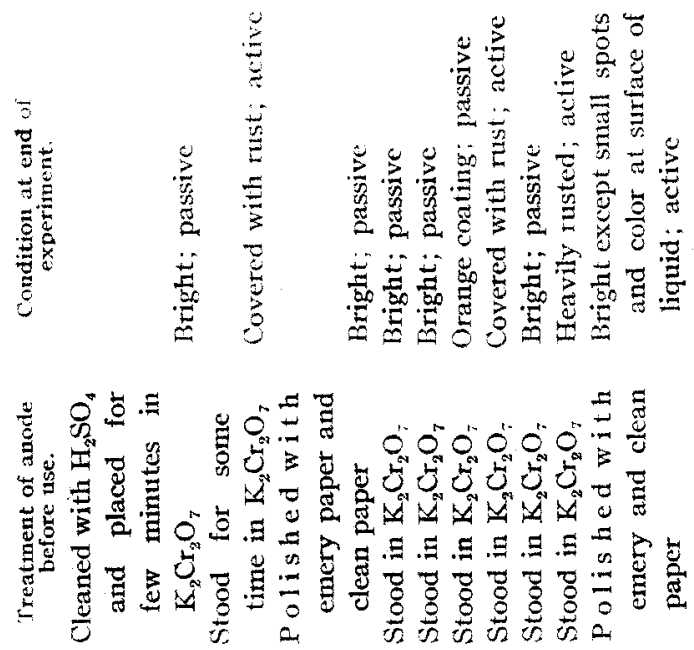

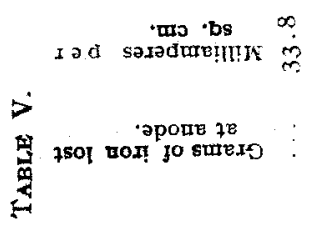

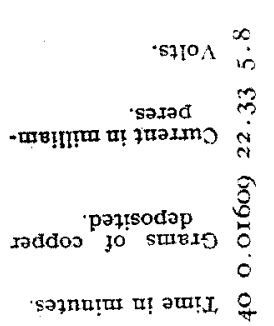

$$
\text { วมกวยมว }
$$

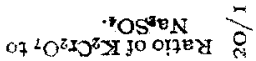

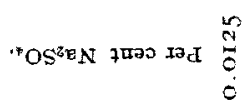

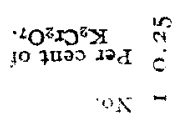

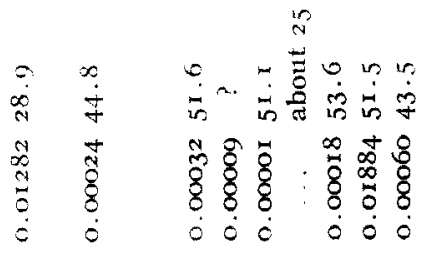

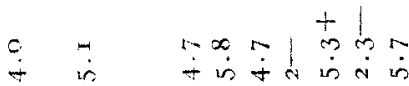

$\Rightarrow$ in $\pm 28,120$

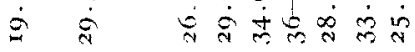

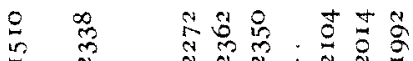

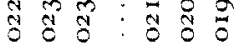

$\dot{0} \dot{0} \dot{0} \dot{0} \dot{0}$

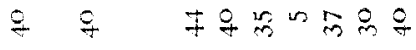

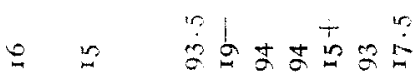

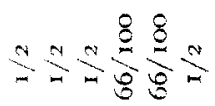

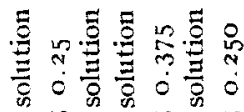

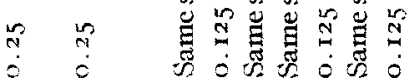




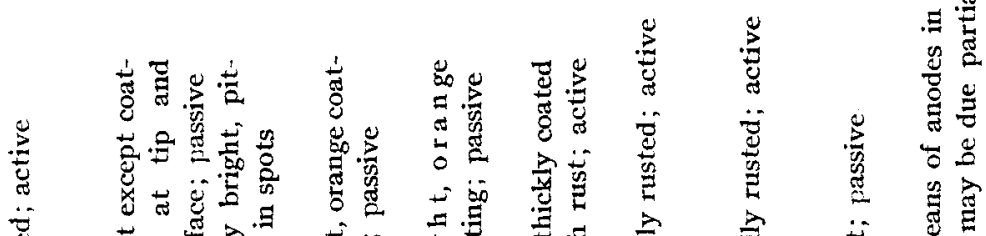

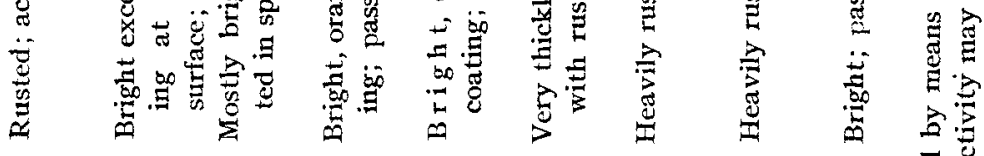

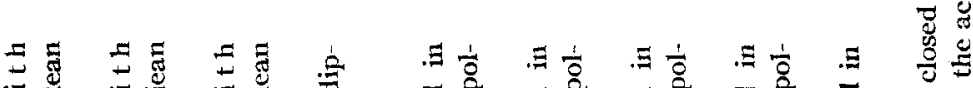

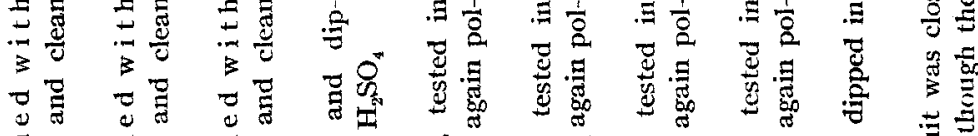

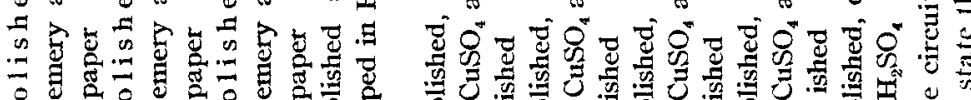

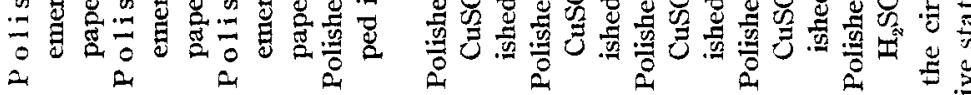

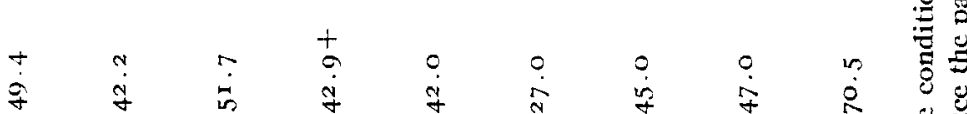

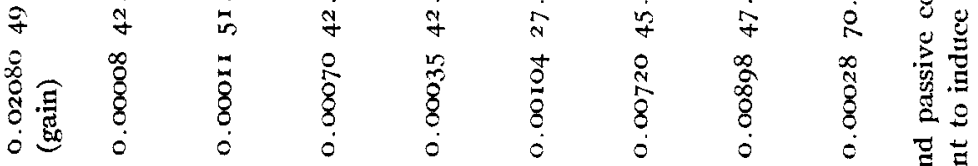

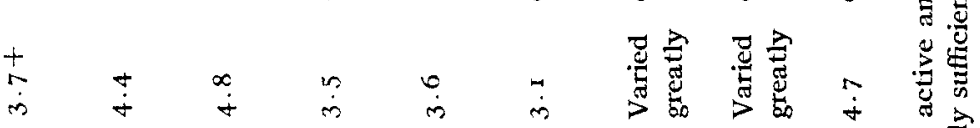

के के

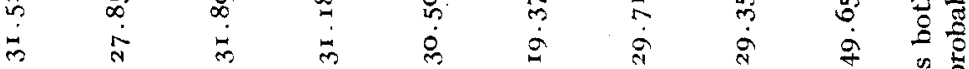

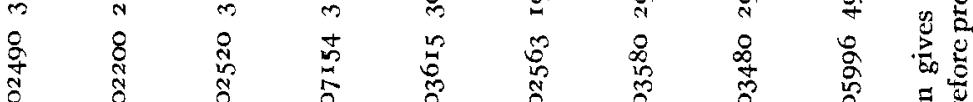

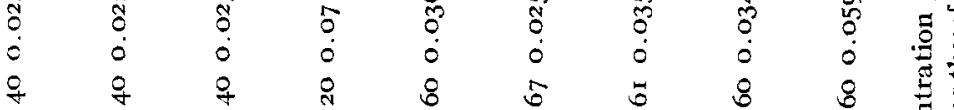

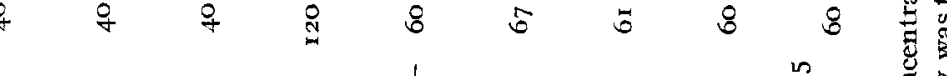

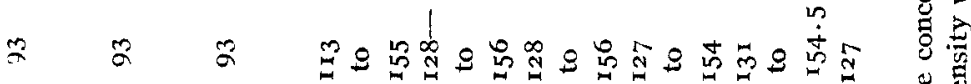

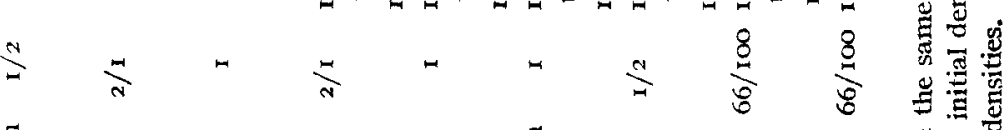

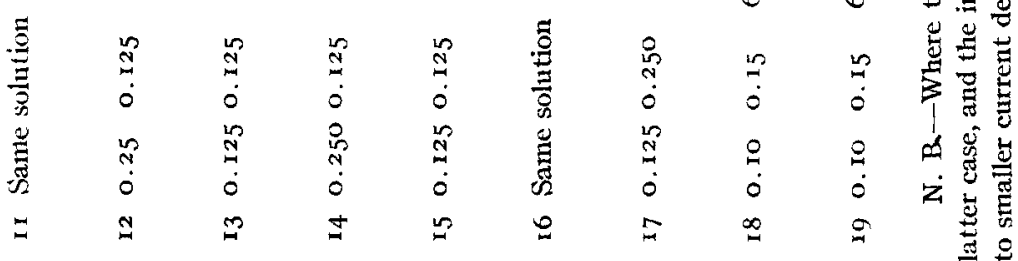




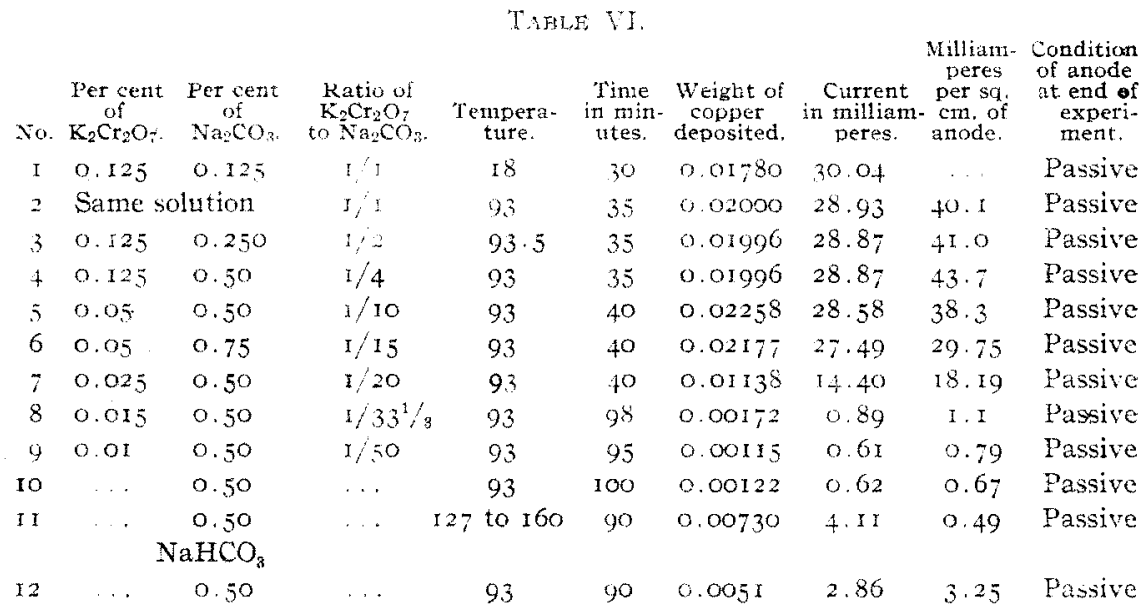

that a density of 3000 amperes per sq. $\mathrm{cm}$. is not sufficient to render iron passive in such a solution. A tube was prepared in one end of which were sealed two electrodes, one of iron wire and one of platinum; the iron was then rendered passive by prolonged immersion in bichromate. The bichromate solution was then removed, the tube carefully rinsed and in the opposit end was placed a $1 \%$ solution of sodium chloride. The tube was then attached to a Gaede pump and carefully and completely evacuated. It was then reversed so as to bring the electrodes beneath the salt solution and a current of 40 to 44 milliamperes per sq. $\mathrm{cm}$. was turned on. In a second series the current was connected before submerging the electrodes. No evidence of even temporary passivity could be obtained. No bubbles rose from the anode and an abundant greenish precipitate of ferrous hydroxide was formed. The only value of these experiments lies in further demonstration of the exceedingly destructive effect of halogen salts upon the passive state of iron.

\section{Summary.}

The results detailed in the experimental discussion and tables lead to the following conclusions:

I. Iron as an anode is rendered passive by bichromate solutions of small concentration, as low as $0.125 \%$, and is kept passive even when the anodic current is very small, at temperatures ranging from room temperature to those approximating boiler conditions.

2. In the presence of moderate quantities of common salt the concentration of bichromate required to maintain the passive state is approximately 40 times greater at room temperature; 25 times greater at $93^{\circ}$ and again 40 times greater at $125^{\circ}$ to $150^{\circ}$. No explanation is apparent to the writers for this peculiar fact.

3. In the presence of sodium sulfate of moderate concentrations, an 
equal concentration of bichromate is sufficient to insure passivity of the anode and an even smaller ratio is ordinarily effective even at temperatures as high as $150^{\circ}$.

4. The presence of carbonates and bicarbonates in water seems to have no destructive effect on the passivity induced by bichromate.

5. Since chlorides, sulfates and carbonates represent the common salts found in water, the general conclusion of Cushman seems to be verified at least so far as anodic conditions are concerned and the further fact is established that the suggestion of Wyatt (see introduction) is valuable. It seems probable also that since the percentage of chlorides in boiler water is usually small and easily determined that a valuable boiler preservative is provided by the addition of an amount of bichromate forty times that of the chlorides present, calculated as sodium chloride, plus that needed to precipitate the scale-forming factors. The cost of such preservative agent is not excessive. The doubtful factor in this case is the extent of the influence of the anodic current in producing the results above detailed. Experiments are at present under way to determin how long iron will remain unrusted in such inhibitive solutions in the absence of electrical current.

The work above detailed was rendered possible through the C. M. Warren Fund.

BAGLEY HALI, UNIVERSTTY OF WASHINGTON.

\section{DETERMINATION OF MANGANESE AS SULFATE AND BY THE SODIUM BISMUTHATE METHOD. ${ }^{1}$}

By William Blum.

Received September 5, 1912.

CONTENTS.

I. Introduction. I. Importance of Accurate Manganese Determinations. 2. Sources of Error in Gravimetric Methods. 3. Sources of Error in Volumetric Methods. II. The Bismuthate Method. r. Outline of Method. 2. History of Method. 3. Standardization of Solution. (a) Discussion of Methods; (b) Evidence Based on Reduction and Reoxidation. 4. Preparation of Materials and Solutions: (a) Water; (b) Air; (c) Asbestos; (d) Potassium Permanganate; (e) Permanganate Solutions; ( $f$ ) Stability of Permanganate Solutions; $(g)$ Manganous Sulfate; $(h)$ Sodium Oxalate; (i) Ferrous Sulfate Solutions-Stability; (j) Nitric acid; $(k)$ Bismuthate; $(l)$ Ferric Nitrate; $(m)$ Use of Weight Burets. 5. Standardization of Permanganate with Sodium Oxalate. 6. Standardization of Permanganate with Manganous Sulphate: (a) Standardization of Manganous Sulphate Solutions; $(b)$ Effect of Conditions upon the Standardizations with Manganous Sulfate: (1) Ferrous Sulfate-Permanganate Ratio; (2) Amount of Manganese Present in a Determination; (3) Acidity, Volume, Time of Standing, etc.; (c) Probable Course of Reactions, (d) Conditions Recommended. 7. Agreement of Values Derived from Sodium Oxalate and Manganese Sulfate. 8. Analysis of Pure Permanganate Crystals. 9. Analysis of Manganese Ores. III. Summary

'Published by permission of the Director of the Bureau of Standards. 